\title{
Effects of fats and oils on the quality characteristics of rice scone
}

\author{
Ok Ja Choi, Hee Nam Jung* \\ Department of Food \& Cooking Science, Sunchon National University, Suncheon 57922, Korea
}

\section{유지 종류가 쌀스콘의 품질특성에 미치는 영향}

\author{
최옥자·정희남* \\ 순천대학교 생명산업과학대학 조리과학과
}

\begin{abstract}
The purpose of this study was to investigate the effects of fats and oils on the quality characteristics of rice scones. Butter, fresh cream, olive oil, and coconut oil were used to prepare rice scones, and their color values, spread factors, and hardnesses were measured. Sensory evaluation was also performed. The highest $L$ value was obtained for the rice scones made with butter and the a and $b$ values were significantly high in the rice scones prepared with olive oil. The rice scones using butter and fresh cream exhibited significantly higher spread factors than other cases. High hardness values were obtained for rice scones made with olive and coconut oils. The flavors of the rice scones prepared using butter and coconut oil were strong based on the results of attribute difference tests, and the stiffness was significantly high in rice scones using fresh cream. In the acceptance test, the overall acceptability values were higher in the rice scones prepared with butter, olive oil, and coconut oil compared to those made with fresh cream. The results suggested that olive and coconut oils could be good butter substitutes for rice scones.
\end{abstract}

Key words : scone, rice, quality characteristics, fat, oil

\section{서 론}

스콘은 영국에서 유래된 쿠키의 한 종류로 겉은 바삭하 고 속은 부드러우며 담백한 맛을 가지고 있다(1). 스콘은 많은 시간과 숙련된 노동력이 필요한 발효빵과는 달리 발효 과정 없이 베이킹 파우더를 이용하여 빠르게 팽창시킨 빵이 라는 의미에서 머핀, 팬케이크 등과 함께 퀵브레드로 분류 되기도 한다(2). 스콘의 담백한 맛을 보완하기 위하여 잼, 크림, 버터 등을 곁들여 먹는 것이 일반적이고, 홍차, 커피 등과 잘 어울리며, 식사대용으로도 소비되고 있다.

스콘은 버터, 설탕, 베이킹파우더, 밀가루, 우유, 달갈을 주재료로 하고, 건조과일, 견과류, 치즈, 홍차 등을 섞어 다양한 맛을 내기도 한다(1). 최근에는 버터와 우유, 달걀과

*Corresponding author. E-mail : hnjung@sunchon.ac.kr Phone : 82-61-750-3690, Fax : 82-61-750-3690

Received 27 May 2019; Revised 26 June 2019; Accepted 05 July 2019

Copyright (c) The Korean Society of Food Preservation. All rights reserved.
같은 재료를 식물성 오일, 두유, 생크림, 요거트, 치즈 등으 로 대체하는 베이킹 방법들이 이용되고 있다. 제과제빵류 의 제조에 이용되는 지방은 우유의 지방인 버터, 식물성 지방을 경화한 마가린과 쇼트닝이 주로 이용된다(3). 마가 린과 쇼트닝은 수소화 과정 중 생성되는 트랜스지방으로 인해 심혈관질환, 비만, 당뇨 등과 같은 질환들이 촉진되는 것으로 알려져 있다(4,5). 마가린과 쇼트닝을 대체하여 버 터가 사용되고 있으나 버터 역시 포화지방의 함량이 높아 심혈관질환 및 고콜레스테롤혈증의 원인이 되고 있어 최근 에는 식물성유를 제과제빵에 활용하기 위한 연구들이 발표 되고 있다(4,6). Jung 등(3)은 머핀의 제조에서 버터를 포도 씨유로 대체하였고, 이외에도 올리브유를 쇼트닝의 대체유 지로 사용한 식빵의 품질특성(7), 대두유와 버터의 첨가비 율에 따른 스펀지케이크의 품질특성(8)에 관한 연구가 보고 되었다. 또 Shin 등(9)이 식물성유지의 버터 대체 가능성을 알아보기 위한 호박냉동쿠키의 품질특성에 관한 연구를 보고하였으나, 스콘에 적용한 연구는 전무하다.

건강지향적인 소비자들의 요구에 의해 당류의 양을 줄이 고, 밀가루를 쌀가루, 흑미가루, 오트밀, 아몬드 가루 등으 
로 대체하거나 기능성 재료들을 첨가한 스콘류의 제품 선호 도가 높다. 국내에서도 기능성 쌀(10), 흑미가루(11), 쌀가 루(12) 등을 밀가루의 대체 재료로 이용한 연구들과 아로니 아(13), 맥문동(14), 초석잠과 인삼(15), 모링가잎 분말(16), 렌틸콩(17) 등과 같은 기능성 재료들을 쿠키에 이용한 연구 들이 보고되었다.

쌀은 글루텐을 함유하고 있지 않지만 전분입자의 크기가 작아 쿠키류 제조에서 밀가루를 대체할 수 있는 좋은 소재 가 될 수 있다(16,18-20). 쌀쿠키에 관한 선행연구로는 햄프 시드(20), 히비스커스(21), 민들레(22), 커피(23), 미역(24) 등을 첨가한 연구들이 있다. 또한 쌀쿠키의 품질을 개선시 키기 위한 연구에서 Kang 등(25)은 아밀로스 함량이 $20 \%$ 수준인 중간 아밀로오스 품종이 쌀쿠키의 제조에 적합하다 고 하였고, Kim 등(19)은 효소처리 쌀가루로 제조한 쿠키의 기호도가 비효소처리 쌀가루로 제조한 쿠키에 비해 유의적 으로 높았다고 하였으며, Choi(12)는 쌀가루를 첨가한 울금 쿠키의 품질특성에 관한 연구에서 밀가루의 $50 \%$ 를 쌀가루 로 대체하였을 때 쿠키의 선호도가 가장 높았다고 하였다. 또 Lee 등(26)은 유화제 종류에 따른 쌀쿠키의 물성변화에 관한 연구를 보고하였고, Lee과 $\operatorname{Lim}(27)$ 은 호화쌀가루의 첨가 시 쌀쿠키의 가장 큰 문제점인 삼킨 후 입자의 잔류감 에 대한 선호도를 증가시켰다고 하였으나, 식사대용 쿠키 류인 쌀스콘의 품질개선을 위하여 유지류를 활용한 연구는 거의 없다.

따라서 본 연구에서는 제과류 중 최근 식사대용으로 소 비가 꾸준히 증가하고 있는 스콘의 제조에 쌀가루를 활용하 기 위하여 쌀스콘의 기호도를 향상시킬 목적으로 부재료로 유지를 이용하였다. 즉 버터, 생크림, 올리브오일, 코코넛 오일을 이용한 쌀스콘의 품질특성을 측정한 후 쌀스콘의 품질개선을 위한 기초자료를 제공하고자 하였다.

\section{재료 및 방법}

\section{실험재료}

본 실험에 사용된 쌀가루는 초미립분쇄기로 제분된 수원 542호 쌀가루를 사용하였고, 아몬드가루(Winfood Co., Ltd., Seoul, Korea), 설탕(CJ Cheiljedang Co., Ltd., Seoul, Korea), 베이킹파우더(Ottogi Co., Ltd., Anyang, Gyeonggi, Korea), 소금(CJ Cheiljedang Co. Ltd.), 버터(Lottefoods Co., Ltd., Seoul, Korea), 코코넛오일(Daesang Group Co., Ltd., Seoul, Korea), 생크림(Seoulmilk Co., Ltd., Seoul, Korea), 올리브오일(Olitaria, Forli, Italia), 우유(Namyang Dairy Products Co., Ltd., Seoul, Korea)를 시중에서 구입하여 사용 하였다.

\section{쌀스콘의 제조}

쌀스콘의 배합비는 Table 1 과 같다. 먼저 쌀가루, 아몬드
가루, 설탕, 소금, 베이킹파우더를 믹싱볼에 넣고 서로 섞일 수 있게 반죽기(5KPM5E, Whirlpool Inc., Benton Harbor, MI, USA)에 넣고 비터로 30초간 믹싱하였다. 버터 첨가구 는 차가운 버터 $140 \mathrm{~g}$ 을 넣고 2단에서 2분간 믹싱한 후 우유를 넣고 1 단에서 30 초간 믹싱하여 반죽을 완성하였다. 생크림, 올리브오일. 코코넛오일 첨가구는 혼합된 가루재 료에 차가운 버터 $90 \mathrm{~g}$ 을 넣고 낮은 2단에서 2분간 믹싱한 후 각각의 유지재료 $50 \mathrm{~g}$ 과 우유 $100 \mathrm{~g}$ 을 넣고 1단에서 30 초간 돌려 스콘 반죽을 완성하였다. 완성된 반죽은 비닐 팩에 넣어 냉장 상태로 30 분간 휴지하였고, 휴지된 반죽을 $20 \times 20 \times 20 \mathrm{~mm}$ 의 크기로 성형하여 윗불 $170^{\circ} \mathrm{C}$, 아랫불 16 $0^{\circ} \mathrm{C}$ 의 전기오븐(CPC-102, Dae Yung machinery Co., Seoul, Korea)에서 25 분간 구운 후 30 분 동안 방냉하여 품질특성 분석에 사용하였다.

Table 1. Formula of rice scone with different fats and oils

(g)

\begin{tabular}{ccccc}
\hline Ingredients & Butter & Fresh cream & Olive oil & Coconut oil \\
\hline Rice flour & 200 & 200 & 200 & 200 \\
Almond powder & 50 & 50 & 50 & 50 \\
Sugar & 44 & 44 & 44 & 44 \\
Baking powder & 8 & 8 & 8 & 8 \\
Salt & 1 & 1 & 1 & 1 \\
Butter & 140 & 90 & 90 & 90 \\
Fresh cream & - & 50 & - & - \\
Olive oil & - & - & 50 & - \\
Coconut oil & - & - & - & 50 \\
Milk & 100 & 100 & 100 & 100 \\
\hline
\end{tabular}

\section{색도 측정}

스콘의 색도 측정은 색차계(JC 801S, Color Techno System Co., Tokyo, Japan)를 사용하여 Hunter's value L(백 색도), $\mathrm{a}$ (적색도), $\mathrm{b}$ (황색도) 값을 측정하였다. 이 때 사용된 표준백판은 L: 92.25 , a: 0.58, b: 3.04 이었다.

\section{퍼짐성 측정}

스콘의 퍼짐성 측정은 $\mathrm{AACC}$ 방법(28)에 준하여 측정하 였다. 스콘의 너비는 쌀스콘 6 개를 가로로 정렬하여 길이를 측정한 후, 각각의 스콘을 $90^{\circ}$ 로 회전하여 같은 방법으로 길이를 측정하여 스콘 1 개에 대한 평균너비를 구하였다. 높이는 스콘 6 개를 수직으로 쌓아 올려서 높이를 측정한 다음 스콘 1 개에 대한 평균 높이를 구하였다. 스콘의 퍼짐성 지수는 너비에 대한 높이의 비로 표시하였다.

\section{경도 측정}

스콘의 경도 측정은 Texture Analyzer(TA-XT2i, Stable 
Micro System Co., Surrey, UK)를 이용하여 분석하였고, test speed: $0.5 \mathrm{~mm} / \mathrm{s}$, distance: $3 \mathrm{~mm}$, probe: $5 \mathrm{~mm}$ cylinder로 하여 측정하였다.

\section{관능검사}

스콘의 관능검사는 오후 3시에 실시하였고, 시료의 제시 는 버터, 생크림, 올리브오일 및 코코넛오일을 이용한 스콘 을 각각 2 개씩 물과 함께 제공하였다. 한 개의 시료를 먹고 나면 반드시 물로 입안을 헹구도록 하였으며, 1-2분 지난 후에 다른 시료를 평가하도록 하였다. 스콘의 특성차이 검 사는 표준화합물을 이용한 차이식별검사를 통과한 패널 10 명을 대상으로 하였다. 패널들에게 관능검사 시 사용되 는 용어, 평가기준, 방법 등을 숙지하는 훈련을 2회 실시한 후 본 검사를 실시하였다. 특성차이 검사는 오후 3시에 실시 하였으며, 평가항목은 색, 향미, 단단함, 퍽퍽함으로 4가지 특성을 평가하였다. 각각의 특성은 7점 척도로 평가하였으 며, 1점은 ‘특성이 약하다', 7점은 ‘특성이 강하다'로 평가하 였다. 스콘의 기호도 검사는 건강한 일반인을 대상으로 실 시하였고, 여자 19명, 남자 15명으로 총 34명이 참여하였다. 기호도 검사의 평가항목은 외관, 색, 향미, 맛, 질감 및 전체 적인 기호도이며, 각각의 특성은 7점 척도로 평가하였고, 1점은 '매우 좋지 않다', 7점은 '매우 좋다'로 평가하였 다.(Approval Number: 1040173-201902-HR-006-02)

\section{통계처리}

본 연구의 결과는 IBM SPSS Statistics(20, IBM Corp., Armonk, NY, USA)를 이용하여 분석하였으며, 평균, 표준 편차, 일원배치분산분석 및 Duncan의 다중범위 검정을 실 시하여 시료간의 유의적인 차이를 검증하였다 $(\mathrm{p}<0.05)$.

\section{결과 및 고찰}

\section{스콘의 색도}

유지 종류에 따른 스콘의 색도를 측정한 결과는 Table 2 와 같다. 스콘의 L값은 버터를 이용한 스콘에서 77.32 로 가장 높았고, 그 다음으로 생크림이었으며, 코코넛오일과 올리브오일을 이용한 스콘은 각각 76.34 및 76.05로 유의적 으로 낮았다 $(\mathrm{p}<0.001) . \mathrm{a}$ 값은 올리브오일에서 -0.62 로 가장 높았고, 버터에서 -1.33 으로 가장 낮았다 $(\mathrm{p}<0.001) . \mathrm{b}$ 값은 올리브오일에서 21.36으로 가장 높았고, 생크림에서 17.42 로 가장 낮았다 $(\mathrm{p}<0.001)$. 색도 측정 결과, 버터를 이용한 스콘은 L값이 가장 높고 $\mathrm{a}$ 값이 가장 낮아 가장 밝은 색을 나타냈고, 올리브오일을 이용한 스콘은 L값이 가장 낮은 반면 $\mathrm{a}, \mathrm{b}$ 값은 가장 높게 나타나 색이 어둡고 진한 것으로 나타났다. 이는 본 연구의 예비실험 단계에서 유지의 색도 를 측정한 결과, 버터와 생크림에서는 $\mathrm{L}$ 값이 높았고, 올리
브오일에서는 $\mathrm{L}$ 값은 낮고 $\mathrm{b}$ 값은 높게 측정되어, 스콘의 색은 첨가된 유지의 색에 영향을 받은 것으로 생각된다. Yoo와 Jeong (29)도 쿠키의 색은 당에 의한 maillard 반응과 카라멜화 반응에 의해 크게 좌우되며, 첨가한 유지의 색에 의해서도 영향을 받는다고 하였다. Shin 등(9)의 연구에서 도 유지종류에 따른 호박냉동쿠키의 L값은 77.65-83.25, $\mathrm{a}$ 값은 1.64-6.64, b값은 27.26-37.24의 범위로 호박페이스트 의 첨가로 인해 본 연구의 결과에 비해 다소 높은 값을 보였으나, $\mathrm{L}$ 값은 올리브유, $\mathrm{a}$ 값은 대두유, $\mathrm{b}$ 은 포도씨유 쿠키에서 높게 나타나 쿠키의 색은 쿠키 제조에 이용된 유지 자체의 색에서 다소 영향을 받았다고 하였다.

Table 2. Hunter color value of rice scone with different fats and oils

\begin{tabular}{cccc}
\hline Sample & $\mathrm{L}$ & $\mathrm{a}$ & $\mathrm{b}$ \\
\hline Butter & $77.32 \pm 0.80^{1 \mathrm{la2})}$ & $-1.33 \pm 0.13^{\mathrm{c}}$ & $19.60 \pm 0.96^{\mathrm{b}}$ \\
Fresh cream & $76.71 \pm 1.06^{\mathrm{ab}}$ & $-0.88 \pm 0.02^{\mathrm{b}}$ & $17.42 \pm 1.37^{\mathrm{c}}$ \\
Coconut oil & $76.34 \pm 0.49^{\mathrm{b}}$ & $-0.84 \pm 0.14^{\mathrm{b}}$ & $19.21 \pm 0.96^{\mathrm{b}}$ \\
Olive oil & $76.05 \pm 0.86^{\mathrm{b}}$ & $-0.62 \pm 0.18^{\mathrm{a}}$ & $21.36 \pm 0.61^{\mathrm{a}}$ \\
\hline F-value & $4.386^{* * *}$ & $50.493^{* * *}$ & $25.544^{* * *}$ \\
\hline
\end{tabular}

${ }^{1)}$ Values are Mean \pm SD

${ }^{2)}$ Mean \pm SD with different superscript in a column are significantly different $(\mathrm{p}<0.05)$. ${ }^{* * *} \mathrm{p}<0.001$.

\section{스콘의 퍼짐성}

유지 종류에 따른 스콘의 퍼짐성을 측정한 결과는 Table 3 과 같다. 스콘의 너비는 버터와 생크림을 이용한 스콘에서 각각 $24.32 \mathrm{~mm}, 23.92 \mathrm{~mm}$ 로 높았고 올리브오일을 이용한 스콘에서 $22.41 \mathrm{~mm}$ 로 유의적으로 낮았다 $(\mathrm{p}<0.001)$. 높이는 올리브오일과 코코넛오일을 이용한 스콘에서 각각 19.81 $\mathrm{mm}, 19.19 \mathrm{~mm}$ 로 높았고, 버터와 생크림을 이용한 스콘에 서 각각 $18.06 \mathrm{~mm}, 17.40 \mathrm{~mm}$ 로 유의적으로 낮게 나타났다 $(\mathrm{p}<0.001)$. 퍼짐성지수는 생크림과 버터를 이용한 스콘에서 각각 $1.38,1.35$ 로 높았고, 코코넛 오일을 이용한 스콘에서 1.21 , 올리브오일을 이용한 스콘에서 1.14 로 유의적으로 낮게 나타났다 $(\mathrm{p}<0.001)$. 퍼짐성은 쿠키를 오븐에 굽는 과 정에서 반죽의 높이는 감소하고 상대적으로 너비는 커지게 되는데, 반죽의 점성, 수분함량과 관련이 있으며 첨가 재료 의 이화학적 특성에 의해서도 영향을 받을 수 있다고 하였 다(20,30). 버터는 $14.00-18.00 \%$ 의 수분이 함유되어 있고, 생크림은 버터에 비해 지방함량은 낮고 수분함량은 높으 며, 올리브오일과 코코넛오일은 수분이 거의 없는 특징이 있다(31). 본 연구에서 쌀스콘 제조에 이용된 유지의 수분함 량 측정 결과에서도 버터 $17 \%$, 생크림 $52 \%$, 올리브오일과 코코넛오일에서는 수분함량이 거의 없는 것으로 측정되어 생크림과 버터를 이용한 스콘이 올리브오일과 코코넛오일 에 비해 높은 퍼짐성 지수를 보인 것은 첨가된 지방에 함유 된 수분함량에 영향을 받은 것으로 생각된다. Shin 등(9)도 
쿠키의 퍼짐성은 첨가된 유지의 수분함량과 관련이 있다고 하였으며, Kim과 $\mathrm{Yoo}(30)$ 도 고추장의 첨가량이 증가할수 록 쿠키 반죽의 수분함량이 높아져 굽는 과정에서 건조되는 시간이 지연되어 퍼짐성이 증가하였다고 하였다.

Table 3. Spread factor of rice scone with different fats and oils

\begin{tabular}{cccc}
\hline Sample & Width (mm) & Height $(\mathrm{mm})$ & Spread factor \\
\hline Butter & $24.32 \pm 0.29^{1 / \mathrm{a} 2)}$ & $18.06 \pm 0.65^{\mathrm{b}}$ & $1.35 \pm 0.05^{\mathrm{a}}$ \\
Fresh cream & $23.92 \pm 0.78^{\mathrm{a}}$ & $17.40 \pm 0.65^{\mathrm{b}}$ & $1.38 \pm 0.06^{\mathrm{a}}$ \\
Coconut oil & $23.09 \pm 0.44^{\mathrm{b}}$ & $19.19 \pm 0.94^{\mathrm{a}}$ & $1.21 \pm 0.06^{\mathrm{b}}$ \\
Olive oil & $22.41 \pm 0.48^{\mathrm{c}}$ & $19.81 \pm 0.94^{\mathrm{a}}$ & $1.14 \pm 0.07^{\mathrm{c}}$ \\
F-value & $12.597^{\star \star \star}$ & $18.303^{* \star \star}$ & $24.986^{* \star \star}$ \\
\hline
\end{tabular}

${ }^{1)}$ Values are Mean \pm SD.

${ }^{2)}$ Mean \pm SD with different superscript in a column are significantly different $(p<0.05)$. ${ }^{* * *}<0.001$.

\section{스콘의 경도}

유지 종류에 따른 스콘의 경도를 측정한 결과는 Table 4 와 같다. 스콘의 경도는 올리브오일과 코코넛오일을 이용 한 스콘에서 1.61 및 $1.55 \mathrm{~kg}$ 으로 가장 높았고, 그 다음으로 버터 순이었으며, 생크림을 이용한 스콘에서 $0.59 \mathrm{~kg}$ 으로 가장 낮게 나타났다 $(\mathrm{p}<0.001)$. 쿠키제품의 texture 특성은 재료의 이화학적 특성과 배합비율에 영향을 받게 된다(32). 특히 재료의 수분함량이 쿠키의 경도에 영향을 주는 것으로 알려져 있으며(33), Lee와 Chung(21)은 수분함량이 높을수 록 경도는 낮아진다고 하였다. 본 연구에도 생크림의 이용 한 스콘의 경도가 다른 시료에 비해 유의적으로 낮게 나타 났는데, 이는 기능성 쌀(10), 울금잎 가루(12), 효소처리 쌀 가루(19), 미역분말(24)을 첨가한 쌀쿠키에 관한 연구에서 부재료 첨가에 따른 수분함량 증가 시 경도가 감소한 결과 와 동일하였다.

Table 4. Hardness of rice scone with different fats and oils

\begin{tabular}{cc}
\hline Sample & Hardness $(\mathrm{kg})$ \\
\hline Butter & $1.12 \pm 0.07^{1 \mathrm{~b} 2)}$ \\
Fresh cream & $0.59 \pm 0.04^{\mathrm{c}}$ \\
Coconut oil & $1.55 \pm 0.04^{\mathrm{a}}$ \\
Olive oil & $1.61 \pm 0.06^{\mathrm{a}}$ \\
\hline F-value & $492.315^{* * \star}$ \\
\hline
\end{tabular}

${ }^{1)}$ Values are Mean \pm SD.
${ }^{2}$ Mean $\pm S D$ with different superscript are significantly different $(\mathrm{p}<0.05)$.
${ }^{* * *} \mathrm{p}<0.001$.

\section{스콘의 관능검사}

스콘의 관능검사를 실시한 결과는 Table 5 및 Table 6과 같다. Table 5는 스콘에 대한 특성차이검사(연하다, 또는 약하다 : 1 , 진하다, 또는 강하다 : 7)를 실시한 것이며,
Table 6은 기호도 검사의 결과를 나타낸 것이다. 특성차이 검사 결과에서, 색은 올리브오일을 이용한 스콘에서 6.20 으 로 가장 높았고, 생크림을 이용한 스콘에서 4.00으로 가장 낮게 나타나 올리브오일을 이용한 스콘의 색이 가장 진한 것으로 평가되었다( $<<0.01)$. 향미는 코코넛오일과 버터를 이용한 스콘에서 각각 6.10 및 5.70으로 높았고, 생크림과 올리브오일은 각각 $4.00,3.50$ 으로 나타나 코코넛오일과 버터를 이용한 스콘의 향이 강하게 나타났다 $(\mathrm{p}<0.001)$. 단 단함은 올리브오일과 코코넛오일을 이용한 스콘에서 각각 $5.70,5.20$ 으로 생크림, 버터를 이용한 스콘에 비해 강하게 평가되었다(p<0.001). 퍽퍽함은 생크림을 이용한 스콘에서 5.80 으로 가장 강하게 나타났고, 버터를 이용한 스콘에서 4.10 으로 가장 약하게 평가되었다( $<<0.05)$. 특성차이검사 의 결과, 색은 올리브오일, 향미는 코코넛오일과 버터, 단단 함은 올리브오일과 코코넛오일, 퍽퍽함은 생크림을 이용한 스콘에서 강하게 나타나 색, 향미, 질감 등과 같은 쌀스콘의 특성은 각각의 유지의 특성에 따라 영향을 받음을 알 수 있었다. 기호도 검사 결과에서, 외관에 대한 기호도는 코코 넛오일, 생크림, 버터를 이용한 스콘에서 각각 $5.66,5.57$, 5.14 로 높았고, 올리브오일을 이용한 스콘에서 4.37로 유의 적으로 낮은 선호도를 보였다(p<0.001). 색에 대한 기호도 는 코코넛오일을 이용한 스콘에서 5.77로 가장 높았고, 생 크림을 이용한 스콘에서 3.46 으로 가장 낮았다 $(\mathrm{p}<0.001)$. 생크림을 이용한 스콘에서 색에 대한 기호도가 낮은 이유는 Table 2의 색도의 결과에서 생크림을 이용한 스콘에서 황색 도인 $\mathrm{b}$ 값이 현저히 낮게 나타나 구운 과자 특유의 색이 다른 시료에 비해 약했기 때문으로 생각된다. 향미에 대한 선호도는 버터와 코코넛오일을 이용한 스콘에서 각각 5.09 , 5.03 으로 높았고 생크림과 올리브오일을 이용한 스콘에서 각각 $3.71,4.20$ 으로 낮았다 $(\mathrm{p}<0.001)$. Table 5 의 특성차이검 사의 결과에서 버터와 코코넛오일을 이용한 스콘의 향미가 생크림과 올리브오일을 이용한 스콘에 비해 강하게 나타났 는데, 버터 및 코코넛오일의 향미가 스콘의 기호도에 긍정 적인 영향을 준 것으로 생각된다. 맛과 질감에 대한 기호도 는 버터, 올리브오일 및 코코넛오일을 이용한 스콘에 비해

Table 5. Sensory attribute score of rice scone with different fats and oils

\begin{tabular}{ccccc}
\hline Sample & Color & Flavor & Hardness & Stiffness \\
\hline Butter & $5.10 \pm 0.99^{11 \mathrm{b2})}$ & $5.70 \pm 0.82^{\mathrm{a}}$ & $4.30 \pm 0.48^{\mathrm{b}}$ & $4.10 \pm 0.99^{\mathrm{b}}$ \\
Fresh cream & $4.00 \pm 1.05^{\mathrm{c}}$ & $4.00 \pm 1.15^{\mathrm{b}}$ & $3.60 \pm 0.97^{\mathrm{b}}$ & $5.80 \pm 1.14^{\mathrm{a}}$ \\
Coconut oil & $5.20 \pm 1.32^{\mathrm{b}}$ & $6.10 \pm 0.74^{\mathrm{a}}$ & $5.20 \pm 0.79^{\mathrm{a}}$ & $5.10 \pm 1.10^{\mathrm{ab}}$ \\
Olive oil & $6.20 \pm 0.79^{\mathrm{a}}$ & $3.50 \pm 0.97^{\mathrm{b}}$ & $5.70 \pm 0.82^{\mathrm{a}}$ & $4.90 \pm 1.10^{\mathrm{ab}}$ \\
\hline F-value & $7.264^{* \star}$ & $18.390^{* \star}$ & $14.162^{* \star}$ & $4.163^{*}$ \\
\hline
\end{tabular}

${ }^{1)}$ Values are Mean \pm SD.

${ }^{2}$ Mean \pm SD with different superscript in a column are significantly different $(p<0.05)$. ${ }_{\mathrm{p}}^{*}<0.05,{ }^{* *} \mathrm{p}<0.01,{ }^{* * *} \mathrm{p}<0.001$. 
Table 6. Sensory acceptance score of rice scone with different fats and oils

\begin{tabular}{ccccccc}
\hline Sample & Appearance & Color & Flavor & Taste & Texture & Overall acceptability \\
\hline Butter & $5.14 \pm 1.11^{1 \mathrm{la} 2)}$ & $4.74 \pm 1.15^{\mathrm{b}}$ & $5.09 \pm 1.31^{\mathrm{a}}$ & $5.11 \pm 0.99^{\mathrm{a}}$ & $5.26 \pm 1.17^{\mathrm{a}}$ & $4.83 \pm 1.40^{\mathrm{a}}$ \\
Fresh cream & $5.57 \pm 1.07^{\mathrm{a}}$ & $3.46 \pm 1.20^{\mathrm{c}}$ & $3.71 \pm 1.27^{\mathrm{b}}$ & $4.23 \pm 1.59^{\mathrm{b}}$ & $4.17 \pm 1.48^{\mathrm{b}}$ & $3.91 \pm 1.15^{\mathrm{b}}$ \\
Coconut oil & $5.66 \pm 1.14^{\mathrm{a}}$ & $5.77 \pm 0.84^{\mathrm{a}}$ & $5.03 \pm 1.22^{\mathrm{a}}$ & $5.20 \pm 1.21^{\mathrm{a}}$ & $4.94 \pm 1.00^{\mathrm{a}}$ & $5.20 \pm 1.13^{\mathrm{a}}$ \\
Olive oil & $4.37 \pm 1.11^{\mathrm{b}}$ & $4.83 \pm 0.92^{\mathrm{b}}$ & $4.20 \pm 0.99^{\mathrm{b}}$ & $5.06 \pm 1.30^{\mathrm{a}}$ & $5.00 \pm 1.51^{\mathrm{a}}$ & $4.69 \pm 1.28^{\mathrm{a}}$ \\
\hline F-value & $9.847^{* * *}$ & $29.359^{* * *}$ & $10.630^{* *}$ & $4.270^{* *}$ & $4.465^{* *}$ & $6.597^{* * *}$ \\
\hline
\end{tabular}

${ }^{1)}$ Values are Mean \pm SD.

${ }^{2)}$ Mean $\pm S D_{* * t}$ with different superscript in a column are significantly different $(\mathrm{p}<0.05)$ ${ }^{* *} \mathrm{p}<0.01,{ }^{* * *} \mathrm{p}<0.001$.

생크림을 이용한 스콘에서 유의적으로 낮았다 $(\mathrm{p}<0.01)$. 스 콘은 쿠키의 한 종류로 분류되지만 바삭한 질감이 높은 선호도를 갖는 일반적인 쿠키류와는 달리 바삭함과 촉촉함 이 동시에 요구되는 제과류로 생크림 스콘의 경우 Table 4 의 결과에서 보듯이 다른 시료에 비해 경도가 낮고 바삭한 질감이 강해 낮은 선호도를 보인 것으로 생각된다. 전체적 인 기호도도 맛과 질감에 대한 선호도 결과와 마찬가지로 생크림을 이용한 스콘에 비해 버터, 올리브오일 및 코코넛 오일을 이용한 스콘에서 높았다 $(\mathrm{p}<0.001)$. 특성차이검사와 기호도검사의 결과에서 보듯이 유지의 종류에 따라 쌀스콘 의 색, 향미, 단단함, 퍽퍽함 강도의 차이가 있었고, 외관, 색, 향미, 맛, 질감 및 전체적인 기호도에 차이를 보였으며, 쌀스콘의 관능적 측면에서 버터를 대체할 유지로는 올리브 오일과 코코넛오일이 적합할 것으로 생각된다.

\section{요 약}

본 연구는 유지의 종류가 쌀스콘의 품질특성에 미치는 영향을 알아보기 위하여 버터, 생크림, 올리브오일, 코코넛 오일을 이용하여 쌀스콘을 제조하고, 색도, 퍼짐성, 경도, 관능검사를 측정하였다. 색도 측정 결과, $\mathrm{L}$ 값은 버터를 이 용한 스콘에서 높았고, $\mathrm{a}$ 값과 $\mathrm{b}$ 값은 올리브오일을 이용한 스콘에서 유의적으로 높았다. 퍼짐성지수는 올리브오일과 코코넛오일에 비해 버터와 생크림을 이용한 스콘에서 높았 다. 경도는 올리브오일과 코코넛오일을 이용한 스콘에서 유의적으로 높았다. 특성차이검사 결과, 버터와 코코넛오 일을 이용한 스콘이 향미 특성이 강하게 평가되었고, 생크 림을 이용한 스콘은 퍽퍽함이 유의적으로 강하게 평가되었 다. 쌀스콘의 기호도 검사 결과, 전체적인 선호도는 생크림 을 이용한 스콘에 비해 버터, 올리브오일, 코코넛오일을 이용한 스콘에서 높았다. 따라서 쌀스콘의 제조 시 버터를 대체할 유지류로 올리브오일이나 코코넛오일의 활용은 쌀 스콘의 품질향상을 기대할 수 있을 것으로 사료된다.

\section{감사의 글}

본 연구는 2017년 전라남도농업기술원의 쌀산학협력사 업으로 수행된 연구 결과의 일부로 이에 감사드립니다.

\section{References}

1. Park SH (2006) Scone. Monthly Bakery, 8, 130-131

2. Roßle C, Ktenioudaki A, Gallagher E (2011) Inulin and oligofructose as fat and sugar substitutes in quick breads (scones): a mixture design approach. Eur Food Res Technol, 233, 167-181

in quick breads (scones): a mixture design approach

3. Jung KI, Shin ES, Kim SA (2008) Quality characteristics of muffins with different fat and methods. Korean J Food Cook Sci, 24, 473-479

4. Choi SN, Chung NY (2006) Quality characteristics of pound cake with vegetable oils. Korean J Food Cook Sci, 22, 808-814

5. Ha JH, Seo DG (2006) Trans fat in foods. Food Sci Ind, $39,18-23$

6. Chung NY, Choi SN (2006) Quality characteristics of pound cake with olive oil. Korean J Food Cook Sci, 22, 222-228

7. Im SH, Yun MS, Lee JH, Min SG, Lee SK (2005) Quality characteristics of white pan bread with olive oil. J Korean Soc Appl Biol Chem, 48, 217-221

8. Yang HY, Cho YJ, OH SS, Park KH (2003) Effects of ratio and temperature of soybean oil or butter on the quality of sponge cake. Korean J Food Sci Technol, 35, 856-864

9. Shin DS, Yoo YM, Park BR (2014) Quality characteristics of iced pumpkin paste cookies prepared using different fat and fatty oils. Korean J Food Cook Sci, 30, 509-516 
10. Kim HYL, Lee IS, Kang JY, Km GY (2002) Quality characteristics of cookies with various levels of functional rice flour. Korean J Food Sci Technol, 34, 642-646

11. Kim YS, Kim GH, Lee JH (2006) Quality characteristics of black rice cookies as influenced by content of black rice flour and baking time. J Korean Soc Food Sci Nutr, $35,499-506$

12. Choi SH (2012) Quality characteristics of Curcuma Longa L. cookies prepared with various levels of rice flour. Korean J Culinary Res, 18, 215-226

13. Lee JH, Choi JE (2016) Quality Characteristics and antioxidant activities of cookies supplemented with aronia powder. J Korean Soc Food Sci Nutr, 45, 1071-1076

14. Lee HJ, Kim MJ, Lee SY, Kim DH, Kim WB, Park SH, Lee HS (2017) Characterization and process optimization of cookies prepared with steamed liriopis tuber extract using response surface methodology. J Korean Soc Food Sci Nutr, 46, 381-388

15. Na BR, Lee JH (2017) Antioxidative capacities of stachys sieboldii MIQ and ginseng powders and their effects on quality characteristics of cookies. J Korean Soc Food Sci Nutr, 46, 68-76

16. Choi SH (2018) Quality characteristics and antioxidant activity of cookies added with moringa (Moringa oleifera Lam.) leaf powder. Culi Sci Hos Res, 24, 102-111

17. Jeong HK (2019) Quality characteristics of cookies with lentil bean powder. Culi Sci \& Hos Res, 25, 34-42

18. Ju JE, Nam YH, Lee KA (2006) Quality characteristics of sponge cakes with wheat-rice composite flour. Korean J Food Cook Sci, 22, 923-929

19. Kim MS, Park JD, Lee HY, Kum JS (2013) Effect of rice flour prepared with enzyme treatment on quality characteristics of rice cookies. J Korean Soc Food Sci Nutr, 42, 1439-1445

20. Ryu JH, Chung HJ (2018) Quality characteristics and antioxidant activity of rice cookies added with hempseed powder. Korean J Food Nutr, 31, 478-484

21. Lee JO, Chung HJ (2018) Quality characteristics and antioxidant properties of rice cookies amended with hibiscus powder. J Korean Soc Food Cult, 33, 451-457
22. Byeon YS, Ra HN, Kim HY (2017) Antioxidant activity and sensory characteristics of rice cookies containing dandelion complex powder. Korean J Food Sci Technol, 49, $173-180$

23. Seong JH, Chung HS, Kim HB, Lee JB, Moon KD (2014) Quality characteristics of rice cookies as affected by coffee addition. Korean J Food Preserv, 21, 40-45

24. Jung KJ, Lee SJ (2011) Quality characteristics of rice cookies prepared with sea mustard (Undaria pinnatifida Suringer) powder. J Korean Soc Food Sci Nutr, 40, 1453-1459

25. Kang TY, Jo HE, Sohn KH, Yoon MR, Lee JS, Lee S, Ko S (2016) Effect of rice variety on the processability for preparing rice cookies. Korean J Food Sci Technol, $48,492-495$

26. Lee JK, Jeong JH, Lim JK (2012) Effects of emulsifiers on physical properties of rice cookies. J Korean Soc Food Sci Nutr, 41, 1565-1570

27. Lee JK, Lim JK (2013) Effects of pregelatinized rice flour on the textural properties of gluten-free rice cookies. J Korean Soc Food Sci Nutr, 42, 1277-1282

28. AACC International (2000) Approved method of the american association cereal chemists. $10^{\text {th }}$ ed. AACC International, St Paul, MN, USA

29. Yoo SS, Jeong HC (2011) Quality characteristics of cookies different with various fat. J East Asian Soc Dietary Life, 21, 905-910

30. Kim DY, Yoo SS (2017) Quality characteristics and antioxidant activities of cookies added with Gochujang. J East Asian Soc Dietary Life, 27, 148-158

31. Yu TJ, Lee SG, Kim DJ (1998) Food processing. Munundang, Seoul, Korea, p 20

32. Olewnik MC, Kulp K (1984) The effect of mixing time and ingredient variation on farinograms of cookie doughs. Cereal Chem, 61, 532-537

33. Oh CH, Kang CS (2016) Effects of apple pomace on cookie quality. Culi Sci Hos Res, 22, 89-98 